\title{
Gold nanoparticle-choline complexes can block nicotinic acetylcholine receptors
}

\author{
This article was published in the following Dove Press journal: \\ International Journal of Nanomedicine \\ 8 May 2010 \\ Number of times this article has been viewed
}

\author{
Chur Chin' \\ In Kyeom Kim² \\ Dong Yoon $\mathrm{Lim}^{3}$ \\ Ki Suk Kim ${ }^{4}$ \\ Hyang Ae Lee ${ }^{4}$ \\ Eun Joo $\mathrm{Kim}^{4}$ \\ 'Department of Pediatrics, Fatima \\ Hospital, Daegu, Korea; ${ }^{2}$ Department \\ of Pharmacology, School of Medicine, \\ Kyungpook National University, \\ Daegu, Korea; ${ }^{3}$ Department of \\ Pharmacology, School of Medicine, \\ Chosun University, Gwangju, Korea; \\ ${ }^{4}$ Korea Institute of Toxicology, \\ Daejeon, Korea
}

\begin{abstract}
We identified a novel class of direct ion-channel blockers of ligand-gated ion channels called the gold nanoparticle-choline complex. Negatively charged gold nanoparticles $(1.4 \mathrm{~nm})$ block ion pores by binding to the sulfur group of the cysteine loop of nicotinic acetylcholine receptors (nAChRs), and currents evoked by acetylcholine (Ach) can break these bonds. The current evoked by ACh in nAChRs was blocked directly in ion pores by the gold nanoparticle-choline complex. In adrenal-gland perfusion studies, the complex also blocked nAChRs by diminishing catecholamine release by about $75 \%$. An in vivo study showed muscle relaxation in rats after injection of the complex. These results will foster the application of gold nanoparticles as a direct ion-channel blocker.
\end{abstract}

Keywords: negatively charged gold nanoparticle, choline, gold-sulfur bond, nicotinic acetylcholine receptor, direct ion-channel blocker

\section{Introduction}

Nicotinic acetylcholine receptors are ion receptors that control the ion pathways of cell membranes through ligands (ie, ligand-gated ion channels). At high concentrations, above $100 \mu \mathrm{M}$, choline can block muscular nAChRs at the selectivity filter, suggesting regulation of the activation gate. ${ }^{1} \mathrm{An} \mathrm{nAChR}$ has five subunits and a binding site for Ach, which is located outside the $\alpha$ subunits in the muscular receptors. When ACh binds to the binding site, the ion path remains open, allowing positive ions to enter the cell. This process leads to structural change in each subunit. ${ }^{2}$

Recently, gold nanoparticles were applied to cancer detection by adding nanoparticle-bound antibodies to cells, and they have been used in molecular imaging because of their unique mechanical, chemical, and electrical properties. The numerous properties of $1.4 \mathrm{~nm}$ negatively charged gold nanoparticles make them attractive candidates as ion-channel blockers, especially to cysteine loop superfamily receptors: small size to enter the extracellular vestibule, stability due to conjugation between the gold nanoparticle and the adjacent sulfur group, less toxicity than fullerenes and other metallic nanoparticles, and ease of separation from weak ionic bonds.

Negatively charged nanoparticles can block the ion pores of ligand-gated ion channels when they are introduced into the pores via other molecules. ${ }^{3}$ Choline $(0.55 \mathrm{~nm})$ is a good candidate for introducing gold nanoparticles into the extracellular vestibule ( $3 \mathrm{~nm}$ diameter) of the receptors (Figure 1). ${ }^{1}$

The identification of new classes of molecules to target ion pores is of significant interest in drug discovery because if these molecules can directly block ion pores, the
Correspondence: Chur Chin

Sangil-dong, Kangdong-gu,

| 34-793, Seoul, Korea

Tel +82 24277297

Email churchin@ymail.com 


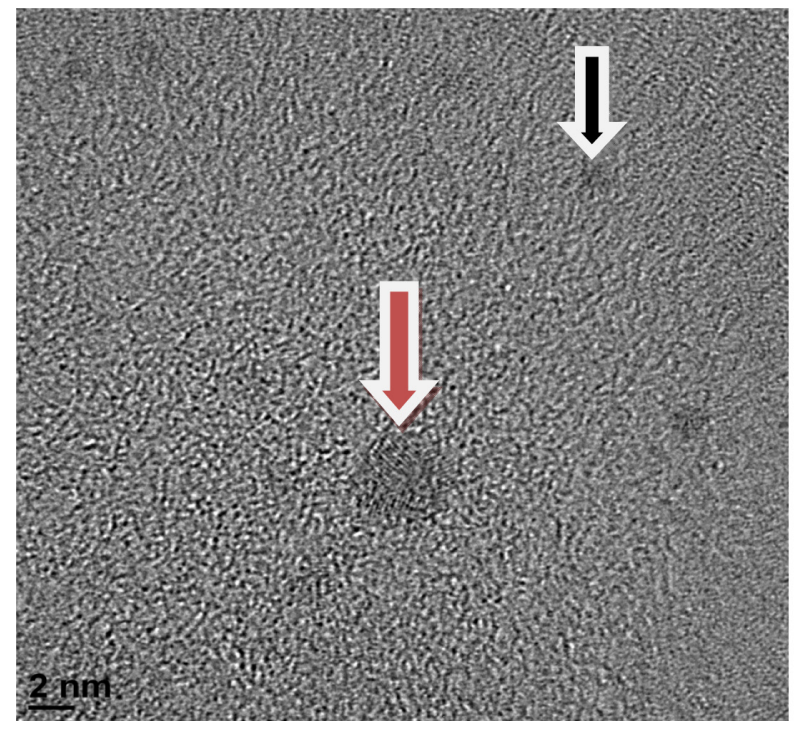

Figure I Gold nanoparticles in the extracellular vestible of receptors.

blocking effects of the channel are increased and no other channels are blocked. Direct blocking of the ion pores of nAChRs could be applied clinically as a potent intravenous anesthetic therapy with fewer side effects. Therefore, we explored the possibility of using a novel material such as gold nanoparticles as a direct ion-channel blocker.

\section{Material and methods}

Local ethical approval was received for conducting the study.

\section{Materials}

The $1.4 \mathrm{~nm}$ negatively charged gold nanoparticles were purchased from Nanoprobes, Inc (New York, NY). The ionic bond was induced by vortexing $1 \mathrm{mM}$ positively charged choline and $15 \mathrm{nM}$ negatively charged gold nanoparticles for about 15 min followed by mixing with a pipette for $15 \mathrm{~min}$. The negatively charged $\mathrm{CoO}^{-}$particles coated on the thin film of nanoparticles bound to the $\mathrm{N}^{+}$group of the choline molecule. Choline hydroxide solution was obtained from Sigma-Aldrich (St. Louis, MO). The PC 12 cell line was obtained from the American Type Culture Collection CRL-1721 (Manassas, VA).

\section{Electrophysiology}

We plated the PC 12 cells on collagen and poly-L-lysine-coated coverslips. The cells were cultured on these coverslips for 2-4 days before use. Membrane currents were recorded by using the whole cell voltage clamp method. ${ }^{4}$ The cells on coverslips were placed in a recording bath with an approximate volume of $1.5 \mathrm{~mL}$ and continuously perfused

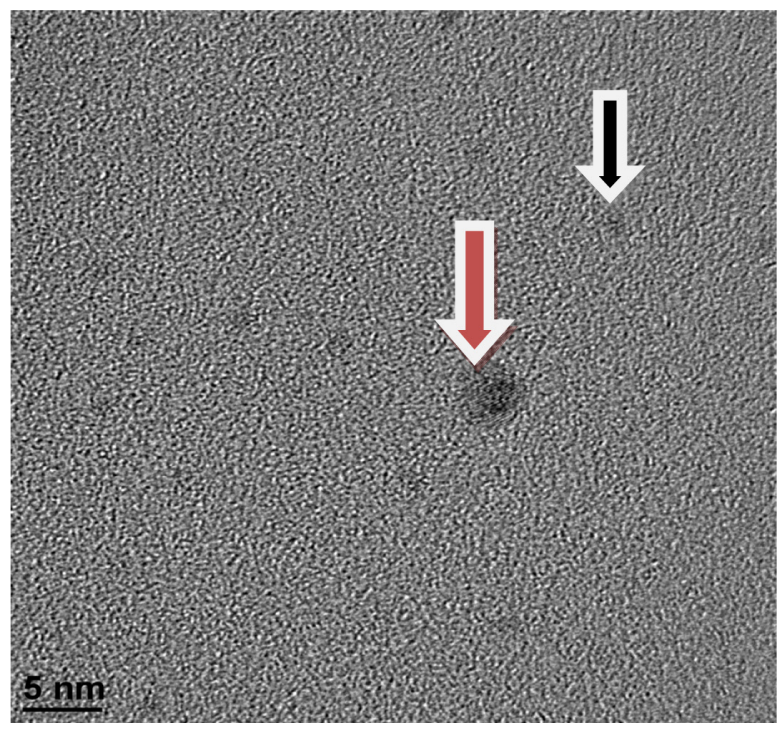

at the rate of $1-2 \mathrm{~mL} \mathrm{~min}^{-1}$ with a standard external solution containing $140 \mathrm{mM} \mathrm{NaCl}, 5.4 \mathrm{mM} \mathrm{KCl}, 1.8 \mathrm{mM} \mathrm{CaCl}_{2}$, $1.0 \mathrm{mM} \mathrm{MgCl}, 10 \mathrm{mM}$ HEPES, and $11.1 \mathrm{mM}$ glucose (titrated to $\mathrm{pH} 7.4$ with $\mathrm{NaOH}$ ). The heat-polished patch pipettes had a tip resistance of 3-7 $\mathrm{M}$ when filled with an intracellular solution containing $150 \mathrm{mM} \mathrm{CsCl}, 10 \mathrm{mM}$ HEPES, $5 \mathrm{mM}$ ethylene glycol tetraacetic acid (EGTA), and $2 \mathrm{mM}$ adenosine triphosphate (ATP)- $\mathrm{Mg}$ (titrated to $\mathrm{pH}$ 7.3 with $\mathrm{CsOH}$ ). The cells were voltage-clamped at $-60 \mathrm{mV}$ with a patch clamp amplifier, Flyscreen 8500 Patch Clamp Robot (Heka Elektronik, Lambrecht/Pfalz, Germany). Whole cell currents were filtered at $0.2 \mathrm{kHz}$ with a Bessel filter and digitized at $1 \mathrm{kHz}$. Data were stored and analyzed on a microcomputer by using pCLAMP software (Axon CNS Molecular Devices, Silicon Valley, CA). All experiments were performed at room temperature $\left(22-25^{\circ} \mathrm{C}\right)$.

\section{In vitro tissue (adrenal gland) study}

Male Sprague-Dawley (SD) rats, weighing 200-300 g, were anesthetized with thiopental sodium $\left(50 \mathrm{mg} \mathrm{kg}^{-1}\right)$ by intraperitoneal injection. The adrenal glands of each rat were isolated by using the Wakade method. ${ }^{5}$ The abdomen was opened with a midline incision, and the left adrenal gland and surrounding area were exposed by using three-hook retractors. The stomach, intestine, and portions of the liver were not removed but pushed over to the right side and covered with saline-soaked gauge pads. Urine was removed from the bladder to obtain enough working space for tying the blood vessels and cannulating. A cannula, used for perfusion of the adrenal gland, was inserted into the distal end of the renal vein after all branches of the adrenal vein (if any), 
vena cava, and aorta were ligated. Heparin (400 $\mathrm{IU} \mathrm{mL}^{-1}$ ) was injected into the vena cava to prevent blood coagulation before the vessels were ligated and cannulated. A small slit was made in the adrenal cortex opposite the entrance of the adrenal vein. Perfusion of the gland was started, ensuring that no leakage occurred and that the perfusion fluid escaped only from the slit in the adrenal cortex. Then, the adrenal gland, along with the ligated blood vessels and the cannula, was carefully removed and placed on the platform of a leucite chamber. The chamber was continuously circulated with water heated at $37^{\circ} \mathrm{C} \pm 1^{\circ} \mathrm{C}$.

The adrenal glands were perfused by using an Isco Wiz peristaltic pump (Teledyne Isco, Lincoln, NE) at the rate of $0.32 \mathrm{~mL} \mathrm{~min}{ }^{-1}$. The perfusion was carried out with Krebs bicarbonate solution of the following composition: $118.4 \mathrm{mM}$ $\mathrm{NaCl}, 4.7 \mathrm{mM} \mathrm{KCl}, 2.5 \mathrm{mM} \mathrm{CaCl}_{2,} 1.18 \mathrm{mM} \mathrm{MgCl}_{2}, 25 \mathrm{mM}$ $\mathrm{NaHCO}_{3}, 1.2 \mathrm{mM} \mathrm{KH} \mathrm{PO}_{4}$, and $11.7 \mathrm{mM}$ glucose. The solution was constantly bubbled with $95 \% \mathrm{O}_{2}$ and $5 \% \mathrm{CO}_{2}$, and the final $\mathrm{pH}$ of the solution was maintained at 7.4-7.5. The solution contained disodium ethylenediaminetetraacetic acid (EDTA, $10 \mu \mathrm{g} \mathrm{mL}^{-1}$ ) and ascorbic acid $\left(100 \mu \mathrm{g} \mathrm{mL}^{-1}\right)$ to prevent oxidation of the catecholamines (CAs).

In addition to a single injection of ACh $(1.2 \pm 0.1 \mu \mathrm{g}$ in a $0.05 \mathrm{~mL}$ buffer solution at room temperature for $4 \mathrm{~min}$ ), the agonistic effect of ACh was confirmed in a control experiment with 1,1-dimethyl-4-phenylpiperazinium iodide (DMPP). The gold nanoparticle-choline complex was readministered 4 min after the initial injection, and the change in CA secretion was measured. Prior to stimulation with various secretagogues, the perfusate was collected for $4 \mathrm{~min}$ to determine the spontaneous secretion of CAs (background sample). Immediately after collection of the background sample, collection of the perfusates was continued in another tube as soon as the perfusion medium containing the stimulatory agent reached the adrenal gland. Perfusate from the stimulated sample was collected from 4 min to 8 min after the injection. The amount secreted in the background sample was subtracted from that secreted in the stimulated sample to obtain the net secretion value of CAs. The buffer solution was perfused every $2 \mathrm{~s}$. Finally, $10 \mu \mathrm{M}$ DMPP stimulation was performed for $2 \mathrm{~s}$ as a reverse condition. The CA content of the perfusate was measured directly by the fluorometric method without the intermediate purification alumina by using a fluorospectrophotometer (Kontron Co, Milano, Italy). A volume of $0.2 \mathrm{~mL}$ of the perfusate was used for the reaction. The CA content in the perfusate of the stimulated glands was high enough to obtain readings several folds greater than the reading of the control samples (unstimulated). The results for the sample blanks were lowest for perfusates of the stimulated and unstimulated samples. The CA content in the perfusate is expressed in terms of norepinephrine (base) equivalents. The data are the average of five replicates.

\section{In vivo electroencephalography}

Six adult SD rats grouped in threes (300-350 g, 10 weeks old) were deeply anesthetized with ketamine, xylazine, and acepromazine $\left(65: 5: 1 \mathrm{mg} \mathrm{kg}^{-1}\right.$ in $2 \mathrm{~mL} \mathrm{~kg}^{-1}$ initial dose and $1 \mathrm{~mL} \mathrm{~kg}^{-1}$ booster, as needed, by intraperitoneal injection) for implantation of a metal U-frame. The frame stabilized the head with screws to a sliding carriage adapter within the stereotaxic frame; electrodes for electroencephalography (EEG) were also implanted. For the EEG, small screws were threaded into the skull to contact the dura over the anteromedial prefrontal, retrosplenial (also the posterior cingulate), parietal, and occipital cortexes of each side and over the olfactory bulb on one side. One screw was inserted in the frontal bone between the frontal lobes and the olfactory bulbs to serve as a reference. After the animals recovered from surgery, they were allowed to accustom to the head fixation for seven days. Within the plexiglas box, the animals were provided with warm blankets $\left(24^{\circ} \mathrm{C}\right)$. The head fixation prevented them from twisting, but they were otherwise able to move their bodies and limbs relatively freely. ${ }^{6}$

\section{In vivo telemetry}

In the in vivo experiments, we monitored activity using the Data Systems International (DSI) telemetry system ${ }^{7}$ after intravenously injecting the rats with the complex. The SD rats (300-350 g) with the implantable transmitters were carefully monitored by recording in the cages. We measured the biopotential activity of the skeletal muscles in the extremities via a sensor implanted in the rat's abdomen.

\section{Results \\ Electrophysiology}

The PC 12 cloned cell line was derived from a CA-secreting tumor of rat adrenal medulla, which has sympathetic neurons. When the cells were voltage-clamped at $-60 \mathrm{mV}$, bath application of $30 \mu \mathrm{M}$ ACh produced an inward current. Next, when treated with the $1 \mathrm{mM}$ choline and $15 \mathrm{nM}$ nanoparticle complex (Figure 2), the peak amplitude was inhibited to near the baseline. This inhibition was reversible and was easily eliminated by a 40-min washout. A solution of $1 \mathrm{mM}$ choline and $30 \mathrm{nM}$ nanoparticles inhibited the peak amplitude completely, probably because of complete occlusion of the ion pores: this effect was not eliminated by washout. 


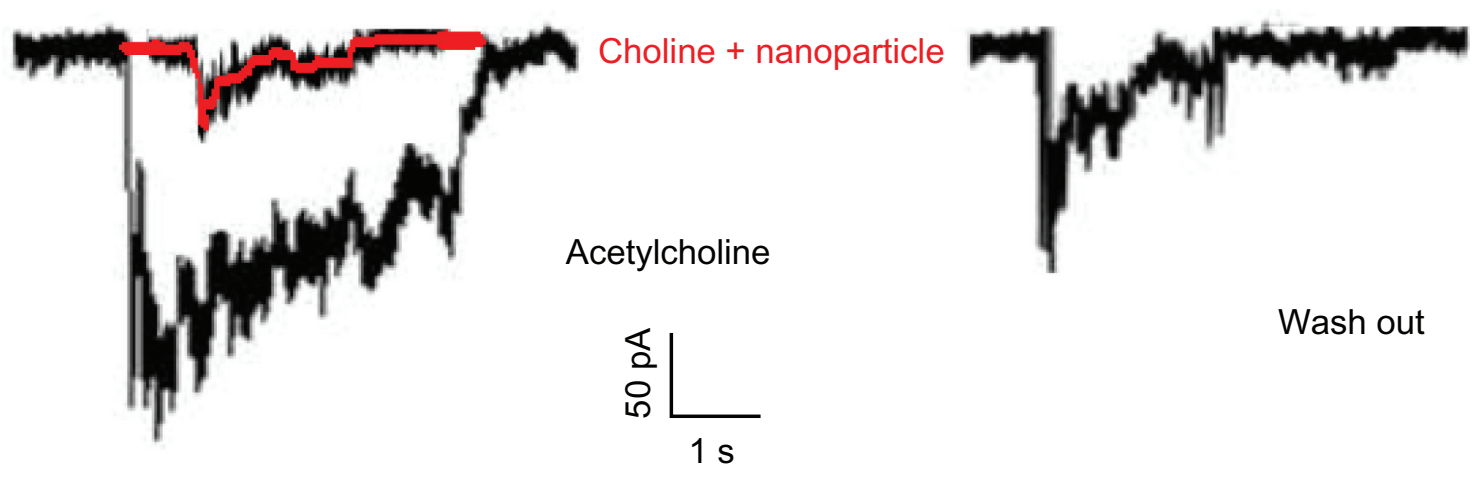

$1 \mathrm{mM}$ choline $+15 \mathrm{nM}$ nanoparticles

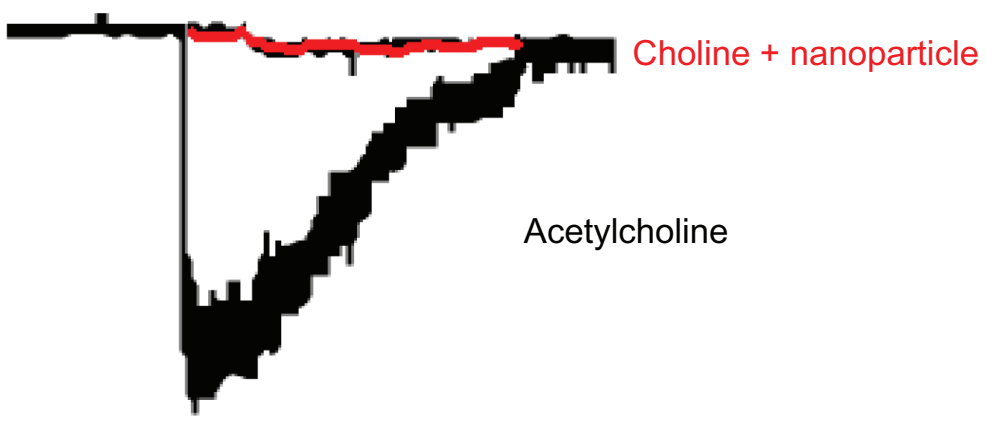

$1 \mathrm{mM}$ choline $+30 \mathrm{nM}$ nanoparticles

Figure 2 Peak amplitude inhibited to near the baseline in PCI2 cloned cell line.

\section{In vitro tissue study}

The secretagogues were administered at 15-min intervals. Gold nanoparticle-choline complexes were detected for $60 \mathrm{~min}$ after the establishment of control release. When the cells were treated with the $1 \mathrm{mM}$ choline and $15 \mathrm{nM}$ nanoparticle complex, we confirmed that the CA secretion evoked by ACh and stimulation of the selective neuronal-type AChR agonist, DMPP, were reduced by about $75 \%$ after 60 min. ${ }^{8}$ When ACh was readministered after about $1.5 \mathrm{hr}$, we confirmed that reversal was achieved (Figure 3).

To exclude mass effects, we also included an intravenous injection of an organic cation substitute, which comprised a $450 \mu \mathrm{L}$ solution containing $1 \mathrm{mM}$ ACh and $15 \mathrm{nM}$ gold nanoparticles. Injection of this solution caused lacrimation and urination in the rats, which are agonistic effects of the $\mathrm{AChR}$ and were not due to the receptor blockage.

\section{In vivo EEG}

The rats were injected with a $450 \mu \mathrm{L}$ solution containing $1 \mathrm{mM}$ choline and $15 \mathrm{nM}$ nanoparticles, a $900 \mu \mathrm{L}$ solution containing $1 \mathrm{mM}$ choline and $15 \mathrm{nM}$ nanoparticles, or a $450 \mu \mathrm{L}$ solution containing $1 \mathrm{mM}$ choline and $30 \mathrm{nM}$ nanoparticles. On injection of the $450 \mu \mathrm{L}$ solution with $1 \mathrm{mM}$ choline and $15 \mathrm{nM}$ nanoparticles, the EEG patterns did not change with muscle paralysis $1 \mathrm{hr}$ later. The rats were deeply anesthetized with loss of consciousness and pain, and they showed no reflexes for another $1 \mathrm{hr}$. During this deep anesthesia, there were no changes in vital signs such as blood pressure and heart rate, which were monitored by catheters in the femoral arteries. Injection of the $900 \mu \mathrm{L}$ solution with $1 \mathrm{mM}$ choline and $15 \mathrm{nM}$ nanoparticles caused immediate muscle relaxation. Injection of the $450 \mu \mathrm{L}$ solution with $1 \mathrm{mM}$ choline and $30 \mathrm{nM}$ nanoparticles caused immediate death. Injection of $15 \mathrm{nM}$ gold nanoparticles only or $1 \mathrm{mM}$ choline only resulted in no definite change on EEG.

\section{In vivo telemetry}

The animals showed intermittent activity after injection of the $450 \mu \mathrm{L}$ solution with $1 \mathrm{mM}$ choline and $15 \mathrm{nM}$ nanoparticles. In contrast, we detected no activity after injection of the 

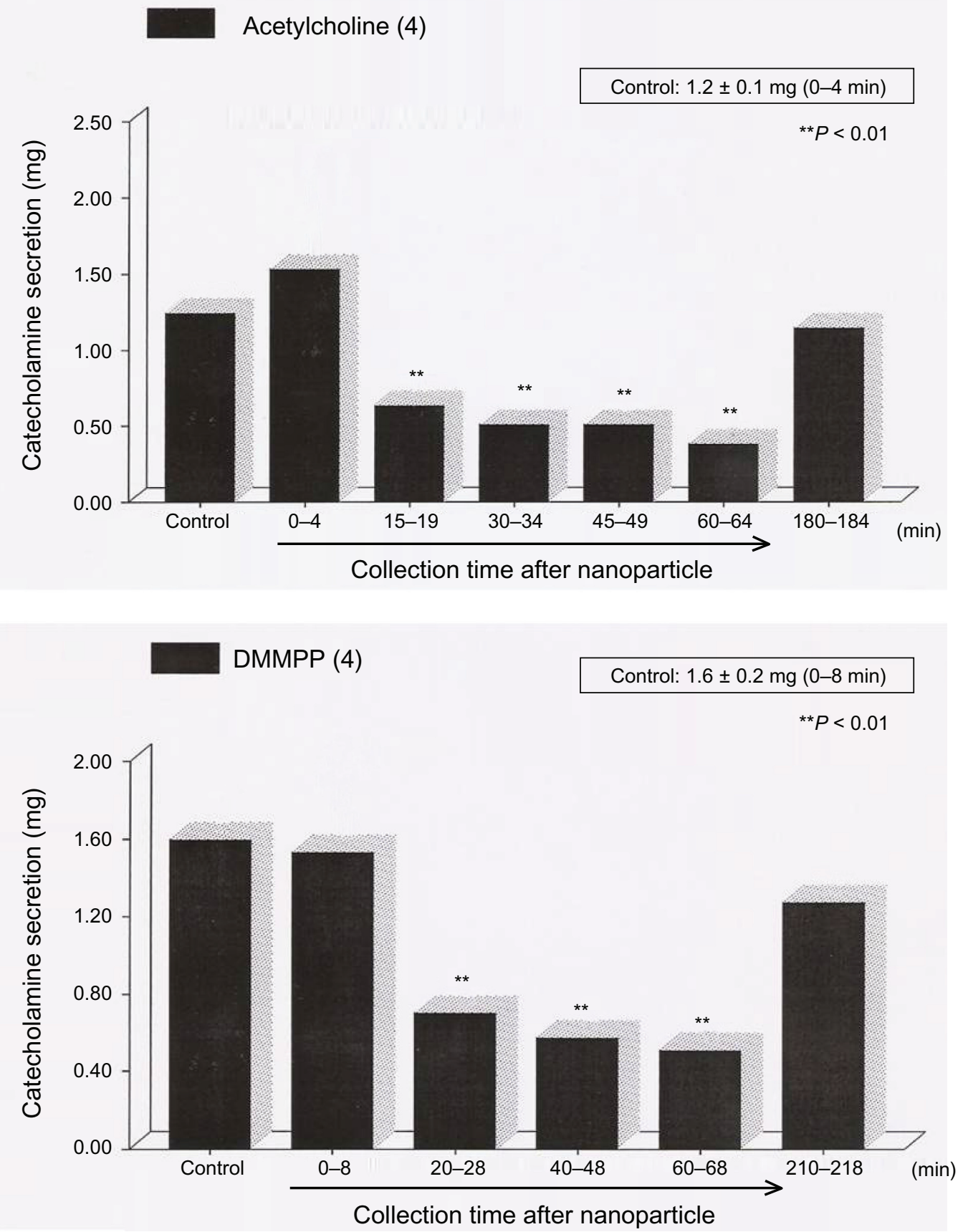

Figure 3 Reversal achieved in catecholamine secretion. Abberviation: DMMPP, dimethyl methyl phosphonate.

$900 \mu \mathrm{L}$ solution with $1 \mathrm{mM}$ choline and $15 \mathrm{nM}$ nanoparticles. The rats injected with the $450 \mu \mathrm{L}$ solution with $1 \mathrm{mM}$ choline and $30 \mathrm{nM}$ nanoparticles died immediately (Figure 4). Injection of $15 \mathrm{nM}$ gold nanoparticles only or $1 \mathrm{mM}$ choline only had no definite effect.

\section{Discussion}

Choline binds to the pore domain with an affinity that does not differ much from the affinity of the transmitter-binding sites for these molecules. The pore-blocking site for choline is the selectivity filter and can hamper the closure of the activation gate. Gold nanoparticles $(1.4 \mathrm{nM})$ constitute a new class of ion-channel inhibitors that directly block ligand-gated nAChRs when accompanied into the ion pore by choline. Blocking of nAChRs caused by the gold nanoparticle-choline complex likely occurs in the ascending reticular activating system of the brainstem, skeletal muscles, and adrenal 


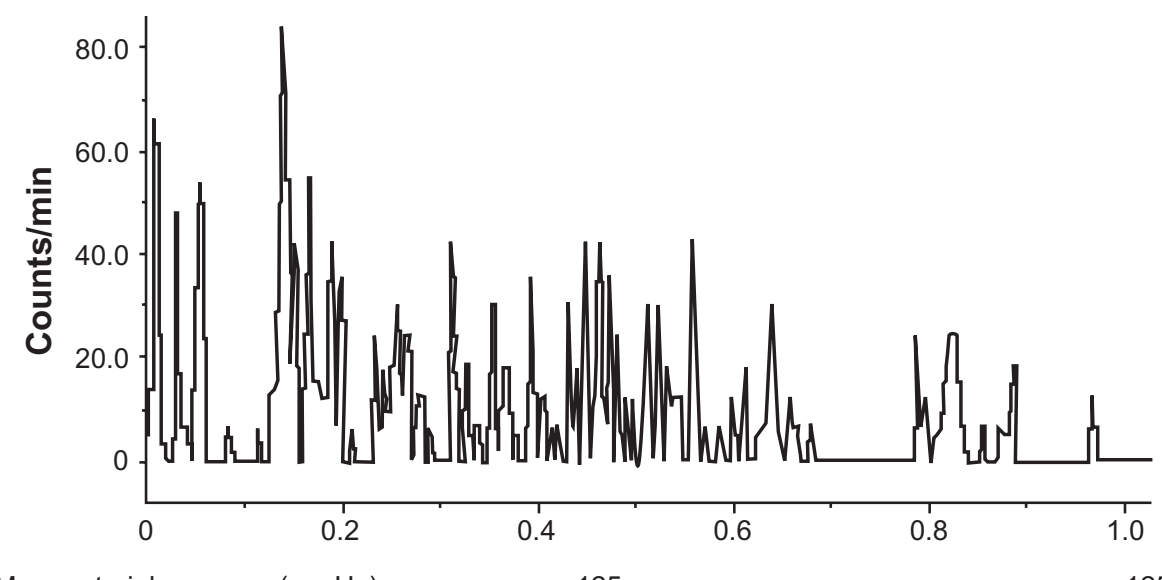

Mean arterial pressure $(\mathrm{mmHg})$

125

125

Corneal reflex

$(+)$

Pain response (tail pinch)

$(+)$

$(+)$

Time (hour)

\section{Normal SD rat $(300-350 \mathrm{~g})$}

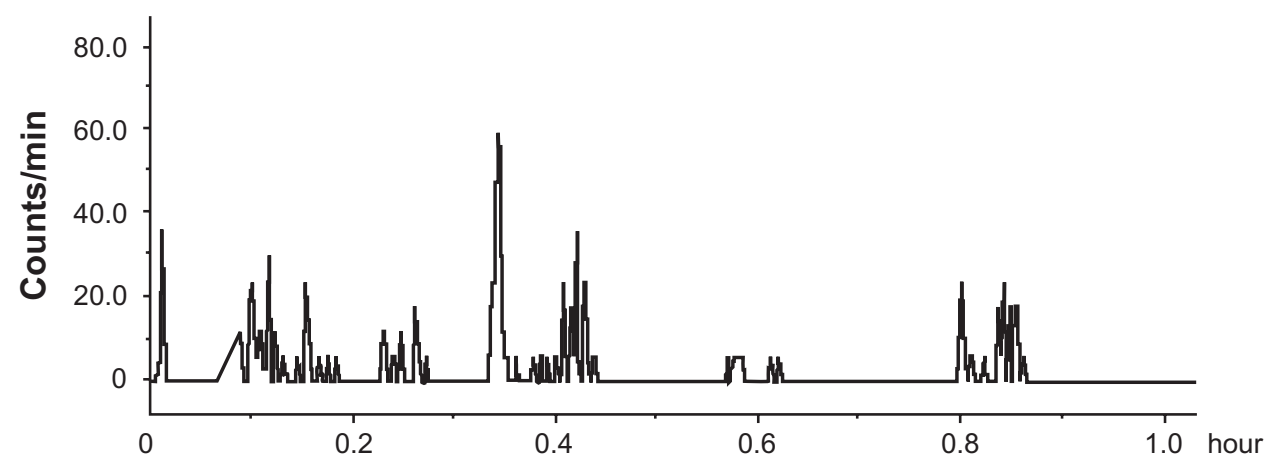

Mean arterial pressure $(\mathrm{mmHg})$

125

125

Corneal reflex

$(-)$

Pain response (tail pinch)

$(+)$

$(-)$

$450 \mu \mathrm{L}$ injection containing $1 \mathrm{mM}$ choice and $15 \mathrm{nM}$ nanoparticle

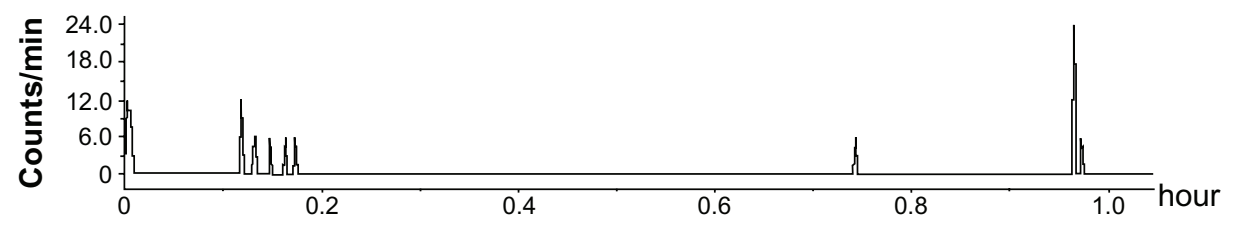

Mean arterial pressure $(\mathrm{mmHg}) \quad 125$

Pain response (tail pinch) (-)

$900 \mu \mathrm{L}$ injection containing $1 \mathrm{mM}$ choline and $15 \mathrm{nM}$ nanoparticle

Figure 4 After injection with choline and nanoparticle solution. 
gland. ${ }^{9}$ The mechanism appears to be governed by the formation and dissolution of gold-sulfur bonds between the gold nanoparticles and the cysteine loop of the nAChRs (Supplement 1). This direct blocking agent has a high therapeutic potential for muscle relaxation in vivo (Supplement 2). and does not cause the blocking effects of any other receptors with similar chemical structures (to view the supplements please click the links above or visit http://dovepress.com/submission_video_10466. php). This study shows that the gold nanoparticle-choline complex has characteristics of direct ion-pore blockers. In our in vivo study, we found that blood pressure was not lowered after injection of the complex, contrary to conventional inhalational or intravenous anesthesia, which suppresses myocardial contractility.

\section{Conclusion}

In conclusion, gold nanoparticles block the function of the channel probably by fitting into the pore and either hindering ion movement or preventing further conformational changes. Here, we have taken a further step in the effort to use gold nanoparticles for therapeutic purposes.

\section{Disclosures}

The authors report no conflicts of interest in this work.

\section{References}

1. Purohit Y, Grosman C. Block of muscle nicotinic receptors by choline suggests that the activation and desensitization gates act as distinct molecular entities. J Gen Physiol. 2006;127:703-717.

2. Uwin N. Structure and action of the nicotinic acetylcholine receptor explored by electron microscopy. FEBS Lett. 2003;555:91-95.

3. Yann A, Oktay U, Francesco S. Electrophysiological study of single gold nanoparticle alpha-hemolysin complex formation: a nanotool to slow down ssDNA through the alpha-hemolysin nanopore. Small. 2009;11:1273-1278.

4. Steven BS, Michael EB. Neuronal nicotinic acetylcholine receptor currents in phaeochromocytoma (PC12) cells: dual mechanisms of rectification. J Physiol. 1992;447:467-487.

5. Wakade AR. Studies on secretion of catecholamines evoked by acetylcholine or transmurali stimulation of the rat adrenal gland. J Physiol (London). 1981;313:463-480.

6. Sukhotinsky I, Zalkind V, Lu J, et al. Neural pathways associated with loss of consciousness caused by intracerebral microinjection of GABAAactive anesthetics. Eur J Neurosci. 2007;5:1417-1436.

7. Brockway BP, Kramer MP. Fully implanted radio-telemetry for monitoring laboratory animals. Lab Animal. 1998;27:40-45.

8. Park KH, Chhowalla M, Iqbal Z, Federico S. Single-walled carbon nanotubes are a new class of ion channel blockers. $J$ Biol Chem. 2003;50:50212-50216.

9. Tassony E. The role of nicotinic acetylcholine receptors in the mechanisms of anesthesia. Brain Res Bull. 2002;57:133-141.
International Journal of Nanomedicine

\section{Publish your work in this journal}

The International Journal of Nanomedicine is an international, peerreviewed journal focusing on the application of nanotechnology in diagnostics, therapeutics, and drug delivery systems throughout the biomedical field. This journal is indexed on PubMed Central, MedLine, CAS, SciSearch ${ }^{\circledR}$, Current Contents ${ }^{\circledR} /$ Clinical Medicine,

\section{Dovepress}

Journal Citation Reports/Science Edition, EMBase, Scopus and the Elsevier Bibliographic databases. The manuscript management system is completely online and includes a very quick and fair peer-review system, which is all easy to use. Visit http://www.dovepress.com/ testimonials.php to read real quotes from published authors. 